\title{
Application of micro-vortex coagulation in the reform of Poyang Waterworks
}

\author{
Hu Fengping ${ }^{1, a}$, Hu Wenjie ${ }^{1, b}$, Peng Xiaojun ${ }^{1, c}$, Huang Bixia ${ }^{1, d}$, Dai Hongling ${ }^{1, e}$ \\ ${ }^{1}$ East China Jiao Tong University,School of Civil Engineering and Architecture, Nanchang, China \\ ahufengping22@126.com, ${ }^{b} 383342936 @ q q . c o m,{ }^{c} 763959550 @ q q . c o m,{ }^{d} 1589734893 @ q q . c o m$, \\ e12569825@qq.com
}

Keywords: Coagulation; Micro-vortex; Reform; Turbidity

Abstract. Due to low efficiency, some water plant in Poyang cannot decrease raw water turbidity availably, which leads to blocking filter tank, shortening backwash cycle and increasing capital. Aiming to those problems, this technical reform bases on micro-vortex flocculation technology, using vortex reactor in either one of the two hole-room flocculation tanks in that plant.After reform and running a certain time, turbidity of treated water before filteration is under $2 \mathrm{NTU}$ and effluent turbidity is inferior to $0.5 \mathrm{NTU}$. On the contrary, those data in unreformed tank is under $4 \mathrm{NTU}$ and $1 \mathrm{NTU}$ respectively.In summary, vortex reactor is apparently improve the flocculation effect.

\section{Introduction}

A new plant processing water $5 \times 10^{4} \mathrm{~m}^{3} / \mathrm{d}$ in Poyang was built in 2010 year. And the raw water takes from Zhu Lake which belongs to Poyang Lake. The plant uses traditional water treatment technology which is coagulation, sediment, filtration and disinfection. However, this method will result in low efficiency of coagulation and cannot decrease raw water turbidity availably. Moreover, not only the filter will be blocked, but also backwash cycle will be shorten and the price is too high. Making sure the effluent quality to reach the standard and decrease the capital, economy, technology, duration and situation are all taken into account by this plant, basing on micro-vortex technology to reform, promoting the flocculation effect of raw water so as to improve effluent quality.

\section{Micro-vortex Coagulation Technology}

Core of micro-vortex coagulation technology is vortex reactor[1,2], and main theory is micro-vortex coagulation and contact flocculation[3,4,5].

The efficiency bases on colloidal solids destabilization degree and impacted probability. (1)Hydrolyzing colloidal solids diffuse rapidly and mix adequately under the action of micro-vortex, which results in those solids destabilizing and settling fleetly. (2)Between each layer of micro-vortex flow, there are differences of velocity and direction. Meantime, under the action of centrifugal force, flocs move along the vortex diameter, which increases the odds of collision to destabilize and improve reaction efficiency of flocculation.

\section{Technological Design and Reform}

\section{Status of Hole Room Flocculation Tanks}

Core of this technological reform is hole-room flocculation tanks, and there are two same tanks (A and B) in this water plant. Each tank can manage $2.5 \times 10^{4} \mathrm{~m}^{3} / \mathrm{d}$ water and owns 10 cells each side. Every cell net size is $2600 \times 2280 \mathrm{~mm}$. Its height and depth is $4.1 \mathrm{~m}$ and $3.2 \mathrm{~m}$ respectively, and flocculation time is $22 \mathrm{~min}$. Fig. 1 shows the schematic diagram of the tank.

The Operation Status of Primary Plant

Tab.1 shows the operatinal parameters of the waterworks. 


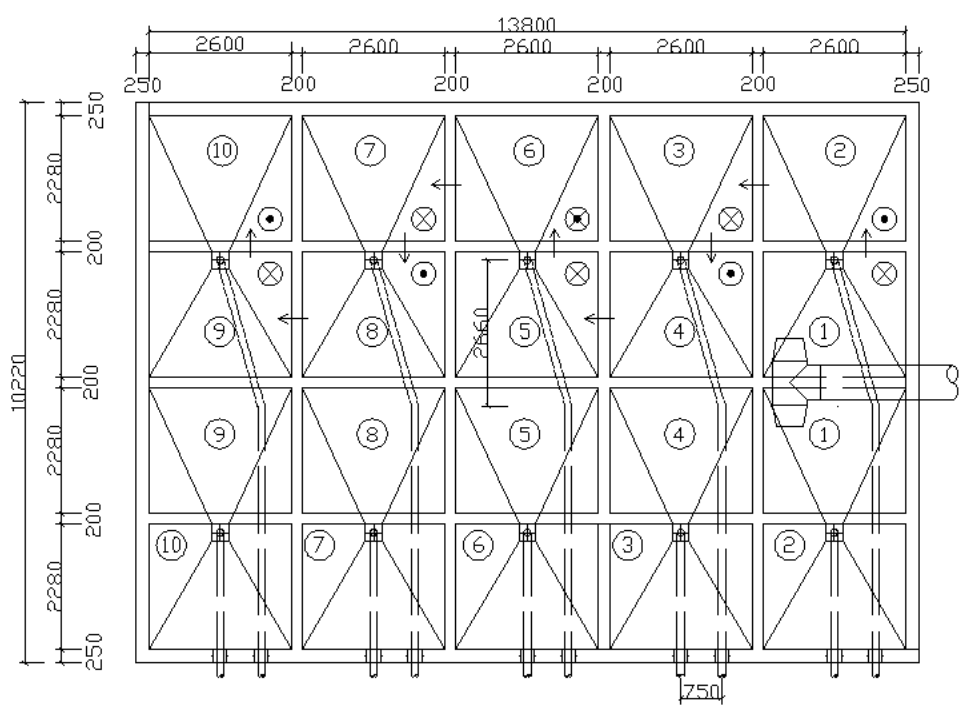

Fig1.Schematic diagram of hole room flocculation tank

Tab.1 operational parameters of the waterworks

\begin{tabular}{|c|c|}
\hline Raw Water Turbidity(NTU) & 3.813 \\
\hline Processing Capacity $\left(\mathrm{m}^{3} / \mathrm{d}\right)$ & $5 \times 104$ \\
\hline Flocculation Time(min) & 22 \\
\hline Proportioning of PAC(\%) & 1 \\
\hline $\begin{array}{c}\text { Opening of Diaphragm } \\
\text { Metering Pump }\end{array}$ & $90 \%$ \\
\hline Dosage (mg/L) & 5.0 \\
\hline Turbidity before filter (NTU) & 3.268 \\
\hline Removal rate of turbidity(\%) & 14.3 \\
\hline Backwash Cycle(h) & 24 \\
\hline Flocs Status in Settling Tank & $\begin{array}{c}\text { Flocs are } \\
\text { small, and } \\
\text { there are less } \\
\text { flocs in } \\
\text { effluent }\end{array}$ \\
\hline
\end{tabular}

Tab.2 operational parameters of changing the dosage

\begin{tabular}{|c|c|}
\hline Raw Water Turbidity(NTU) & 4.446 \\
\hline Processing Capacity(m3/d) & $5 \times 104$ \\
\hline Flocculation Time(min) & 22 \\
\hline Proportioning of PAC(\%) & 0.635 \\
\hline $\begin{array}{c}\text { Opening of Diaphragm } \\
\text { Metering Pump }\end{array}$ & $50 \%$ \\
\hline Dosage(mg/L) & 2.0 \\
\hline Turbidity before filter(NTU) & 3.692 \\
\hline Removal rate of turbidity(\%) & 17 \\
\hline Backwash Cycle(h) & 24 \\
\hline Flocs Status in Settling Tank & $\begin{array}{c}\text { Flocs are } \\
\text { small, } \\
\text { and there } \\
\text { are lots of } \\
\text { flocs in } \\
\text { effluent }\end{array}$ \\
\hline
\end{tabular}

When the dosage of PAC is $2.0 \mathrm{~m} / \mathrm{L}$, and after stable operation, removal rate of turbidity before filtration is $14.3 \%$ and the filter time is 24 hours. The floc size is pretty small, and there are many flocs in settled water. Preliminary scheme is to increase flocculant quantity and the dosage is $5.0 \mathrm{mg} / \mathrm{L}$. After running a period of time, the technology is stable and get relevant data as Tab.2.

The result shows that after increasing dosage of flocculant, although removal rate is up to $17.0 \%$, the turbidity before filter is still 3.692NTU which is greater than 3NTU. This method can neither decrease the processing load of filter nor extend backwash cycle. Above all analysis, the method of increasing dosage is less effect on flocculation process, and cannot improve the poor effect of flocculation.

\section{The Scheme of Design Reform}

(1)The construction of hole-room flocculation tank is invariant. Tank A is added stainless steel 
support in number 2 to 6 cell, $0.6 \mathrm{~m}$ from tank bottom(dimensions: $2570 \mathrm{~mm} \times 2250 \mathrm{~mm}$; Each rail interval is $12 \mathrm{~cm}$ ).

(2)The number 2 to 6 cell are symmetrically put in micro-vortex reaction HJTM-1(external diameter is $20 \mathrm{~cm}$ and bore diameter is $35 \mathrm{~mm}$ ), and the height is $1.6 \mathrm{~m}$.

\section{The Calculation of Design Parameter}

\section{The Reformed Flocculation Reaction Time}

Fig. 2 shows the appearance of the reform cell.

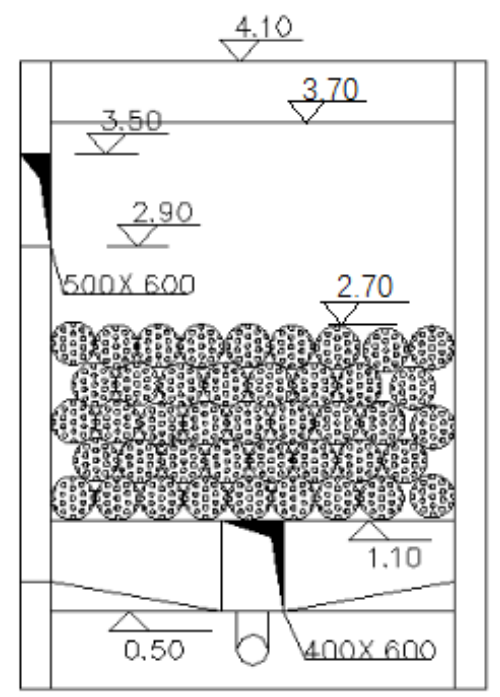

Fig. 2 cross section of hole room flocculation tank

According to the cross section of reformed tank, it is obviously that number 2 to 6 cell are added support, $1.6 \mathrm{~m}$ from tank bottom. Therefore, the volume of micro-vortex zone is:

$\mathrm{V}_{1}=2.28 \times 2.6 \times 1.6 \times 5 \approx 47.4 \mathrm{~m}^{3}$

Micro-vortex reaction time $\mathrm{T}_{1}$ is:

$$
T_{1}=\frac{V_{1}}{Q}=\frac{(2.28 \times 2.6 \times 1.6 \times 5) \mathrm{m}^{3}}{\left(2.5 \times 10^{4} /(2 \times 24 \times 60)\right) \mathrm{m}^{3} / \mathrm{min}} \approx 5.5 \mathrm{~min}
$$

$2.28 \times 2.6 \times 3.2 \times 9 \approx 171 \mathrm{~m}^{3}$

The tank total volume $\mathrm{V}_{2}$ is:

Non-micro-vortex reaction time $\mathrm{T}_{2}$ is :

$$
T_{2}=\frac{V_{2}-V_{1}}{Q}=\frac{(171-47.4) \mathrm{m}^{3}}{\left(2.5 \times 10^{4} /(2 \times 24 \times 60)\right) \mathrm{m}^{3} / \mathrm{min}} \approx 14.2 \mathrm{~min}
$$

The total flocculation reaction

time $\mathrm{T}$ is:

$$
\mathrm{T}=\mathrm{T}_{1}+\mathrm{T}_{2}=5.5+14.2 \mathrm{~min}=19.7 \mathrm{~min}
$$

\section{The Velocity in Micro-vortex Reaction Field}

In micro-vortex field, the velocity should keep in 60 to $80 \mathrm{~m} / \mathrm{h}$. If it exceed safe range, the cover should be used in upwelling field so as to protect reactor from floating.

$$
S=L \times B=2.6 \times 2.28=5.93 \mathrm{~m}^{2}
$$

After reforming, the rising velocity could be calculated:

$V=\frac{Q}{S}=\frac{\left(2.5 \times 10^{4} /(2 \times 24)\right) \mathrm{m}^{3} / \mathrm{h}}{5.93 \mathrm{~m}^{2}}=87.8 \mathrm{~m} / \mathrm{h}$

The result shows that the velocity is not in proper range, so cover should be used.

\section{$\mathbf{G}$ and $\mathbf{G T}$ in flocculation reaction}

After measure and calculation, the head lose of flow from number 2 to 10 cell is $0.3 \mathrm{~m}$, indicating as: 


$$
G=\sqrt{\frac{\gamma h}{\mu T}}=\sqrt{\frac{1000 \times 0.3}{0.1165 \times 10^{-3} \times 19.7 \times 60}} \mathrm{~s}^{-1}=47 \mathrm{~s}^{-1}
$$

It conforms to traditional flocculation control index: average $\mathrm{G}$ is $20-70 \mathrm{~s}^{-1}$, average GT is $1 \times 10^{4}-1 \times 10^{5}$.

\section{Reformed Running Status}

After reforming of hole-room flocculation tank, the whole technology debugs and runs a period of time, comparing with primary tank in water quality. It can be known that the reformed technology is able to reach expected effect. Tab.3 shows the comparison of operational index.

Tab.3 Comparison of operational index

\begin{tabular}{|c|c|c|}
\hline Index & A Tank & B Tank \\
\hline Processing Capacity $(\mathrm{m} 3 / \mathrm{d})$ & $2.5 \times 104$ & $2.5 \times 104$ \\
\hline Dosage $(\mathrm{mg} / \mathrm{L})$ & 5.0 & 5.0 \\
\hline Flocs in reaction tank & Dense and distinct & indistinct \\
\hline Flocculation Time(min) & 19.7 & 22 \\
\hline Turbidity before filter(NTU) & $\leq 2$ & $\leq 4$ \\
\hline Work cycle of filter(h) & 36 & 24 \\
\hline Effluent turbidity(NTU) & $\leq 0.5$ & $\leq 1$ \\
\hline
\end{tabular}

\section{Conclusions}

(1)Before reforming, Enlarging dosage of hole-room flocculation tank is used to keep plant running stably. But the water quality is analyzed to know that the method has little achievement on improving coagulation effect, which cannot availably decrease turbidity of raw water.

(2)The reformed technology is running stably after adding $5 \mathrm{mg} / \mathrm{L}$ PAC.The turbidity of micro-vortex reactor group before filter is distinctly lower than that of regular group. The flocs of primary flocculation tank are small, and have poor settling performance.Its turbidity before filter is under 4NTU while effluent is inferior to 1NTU, the backwash cycle is 24 hours. On the contrary, flocs in reformed tank are dense, and have good performance. The backwash cycle extends to 36 hours, which is better than primary tank.

(3) It is obviously that using micro-vortex technology to improve processing effect in Shangrao plant, which can provide gist for this plant and others to reform and transform.

\section{Acknowledgments}

This work is supported by Natural Science Foundation of JiangXi province(No.20151BAB2030 22); Science and Technology Support Program of Jiangxi Province(No.20161BB1903); Landing Plan of Scientific and Technological Project of Jiangxi Provincial Colleges and Universities(No.KJ CD2013037).

\section{References}

[1] Z.G. Tong, P.P. Lu and Y.S. Chen . China Water \& Wastewater, Forum Vol.4(2012)2, p. 79

[2] P.T. Zhang, F.P. Hu and Q. Zhang. Journal of East China Jiaotong University, Forum Vol. 5(2006), p. 9

[3] J. Guo, Y. Shao. Water Technology, Forum Vol. 6(2010), p. 21

[4] Z.G. Tong, F.P. Hu and Y.Z. Fang. Water \& Wastewater Engineering, Forum Vol.10(2009), p.15 
[5] Y.C. Hu. Industrial Water \& Wastewater, Forum Vol. 1(2009), p. 89 